\title{
ANALISIS KETERTARIKAN PENGGUNA MOBIL PRIBADI TERHADAP RENCANA OPERASIONAL TREM DI SURABAYA (Studi Kasus Pada Koridor Utara-Selatan Kota Surabaya)
}

\author{
Oleh:
Cecep Hidayat ${ }^{1}$, Adhi Muhtadi ${ }^{2}$ \\ ${ }^{1}$ Prodi Teknik Sipil, Universitas Narotama, cecephidyat16@gmail.com \\ ${ }^{2}$ Prodi Teknik Sipil, Universitas Narotama, adhimuhtadi1974@gmail.com
}

\begin{abstract}
ABSTRAK
Tujuan penelitian ini adalah untuk mengetahui seberapa besar potensi masyarakat di Kota Surabaya yang tertarik dan beralih menggunakan Angkutan Masal Cepat (AMC) Trem. Lokasi yang akan saya pakai untuk bahan penelitian adalah mengambil daerah di sepanjang kawasan rencana rute tram pada koridor utara - selatan. Banyak ruas jalan di Surabaya terlihat sangat padat, sehingga terjadi derajat kejenuhan yang tinggi pada ruas - ruas jalan utama Kota Surabaya. Hal ini pula terjadi karena faktor masyarakat yang tidak begitu berminat menggunakan angkutan umum yang dinilai kurang memenuhi kelayakan penumpangnya, maka direncanakanya operasional trem di masa yang akan datang ini untuk memberikan solusi mengatasi kemacetan di Kota Surabaya. Sehingga disusunlah penelitian ini untuk membahas variabel - variabel apa sajakah yang berpotensi untuk meningkatkan ketertarikan masyarakat agar berupaya dan bersedia beralih menggunakan Angkutan Masal Cepat (AMC) Trem. Hasil penelitian ini menunjukan bahwa hubungan variabel - variabel untuk meningkatkan ketertarikan pengguna mobil pribadi terbilang lemah yaitu $15,4 \%$ terlihat dari uji $\mathrm{R}^{2}$, berdasarka uji simultan secara keseluruhan semua variabel independen berpengaruh terhadap variabel dependen yaitu ketertarikan pengguna mobil pribadi beralih menaiki Trem dengan nilai $\mathrm{F}$ tabel $\mathrm{F}$ hitung $>\mathrm{F}$ tabel yaitu 2,828 $>2,34$ yang artinya nilai F hitung lebih besar dari pada $\mathrm{F}$ tabel.
\end{abstract}

Kata kunci : kendaraan, kemacetan, angkutan umum, trem

\section{PENDAHULUAN}

Kemacetan disepanjang jalan merupakan satu dari sekian banyak masalah yang ada di negara kita ini. Seakan - akan kemacetan kerap terjadi karena banyak masyarakaat yang dimanjakan dengan tidak adanya penerapan pembatasan kendaraan pribadi. Jika kita mau berfikir secara logika, biaya bahan bakar kendaraan pribadi jauh lebih boros ketimbang kita menaiki kendaraan umum, terlalu banyaknya kendaraan pribadi di kota kota besar di indonesia ini pun mengakibatkan banyak polusi bagi warga yang berada di sekitarnya.

Pertumbuhan kendaraan pribadi ini pun apabila tidak diimbangi dengan penambahan jumlah panjang jalan dan lebar jalan akan mengakibatkan peningkatan derajat kejenuhan dan kedepanya akan meningkatkan potensi kemacetan pada suatu daerah. Kejadian seperti ini adalah kejadian yang secara umum ada di kota-kota besar di Indonesia baik di propinsi maupun di kabupaten/kota.

Oleh karena itu, pemerintah kota akan mengupayakan angkutan umum yang memadai, guna memberikan alternatif cara pergerakan bagi pelaku pergerakan baik untuk keperluan bekerja, sekolah, berbelanja, wisata dan lain-lainnya. Beroperasinya angkutan 


\section{NAROTAMA JURNAL TEKNIK SIPIL \\ e-ISSN: $2460-3430$ \\ VOLUME 2 NOMOR 2 NOVEMBER 2018}

umum yang telah disediakan oleh pemerintah tidak terlalu diminati oleh pelaku pergerakan sehari-hari, sehingga angkutan umum yang ada seakan-akan terpinggirkan oleh keberadaan kendaraan pribadi yang dimiliki oleh masyarakat.

Problematika seperti ini juga terjadi di Kota Surabaya yang merupakan kota terbesar nomor dua di Indonesia. Jumlah kendaraan pribadi seperti sedan, jeep dan sejenisnya tiap tahunnya mengalami peningkatan yang cukup signifikan. Rata-rata peningkatan jumlah mobildari tahun ke tahun akan terus bertambah apabila tidak ada kebijakan pemerintah untuk membatasinya.

Faktor pertumbuhan adalah tingkat pertumbuhan dalam suatu kawasan yang menggambarkan karakteristik dari wilayah tertentu (Wibisono, 2014). Pertumbuhan kendaraan dari tahun ke tahun, terdapat ketidak seimbangan antara pertumbuhan kendaraan dan perkembangan jalan di Surabaya yang mengakibatkan kemacetan di beberapa ruas, contohnya saja di sepanjang jalan Kota Surabaya sendiri banyak ruas jalan yang mengalami kemacetan diantaranya adalah Jl. Raya Darmo, Jl. Urip Sumoharjo, Jl. Jend. Ahmad Yani, Jl. Gemblongan, Jl. Embong Malang, Jl. Raya Arjuno, Jl.Panglima Sudirman, Jl. Basuki Rahmad, Jl. Wonokromo, Jl. Bubutan, Jl.Tunjungan, Jl. Indrapura, Jl. Perak dan Jl. Pahlawan.

Akibat kemacetan di daerah jalan tersebut akhirnya pemerintah berinisiatif untuk mengoperasikan angkutan umum berupa (angkot dan bus) sayangnya keberadaan angkutan umum tersebut tidak begitu banyak diminati oleh penumpangnya sehingga keberadaanya tersingkirkan oleh kendaraan - kendaraan yang layak dan enak dilihat, apalagi akhir - akhir ini terdapat aplikasi sejenis kendaraan pribadi yang sengaja dipergunakan untuk mengangkut pelaku pengguna jalan sehari - hari.Menanggapi hal tersebut, akhirnya pemerintah berupaya memberikan alternatif baru yaitu sarana angkutan umum yang dapat mengangkut secara massal dan lebih cepat daripada angkutan umum yang sudah ada yaitu Angkutan Massal Cepat.

Angkutan Massal Cepat yang dipilih oleh pemerintah adalah dengan membangun kembali jalan rel yang dulu pernah dilalui operasional trem di Surabaya ketika jaman era belanda pada koridor utara - selatan. Sarana transportasi operasional trem tersebut akan beroperasi di jalur utama, dengan ditunjang oleh bus kota ukuran sedang sebagai pengumpan.

Keberhasilan operasional trem nantinya ditentukan oleh ketertarikan warga Kota Surabaya. Oprasional trem akan berhasil apabila memenuhi standar transportasi yang ditunjang oleh fasilitas transit bagi penumpang yang akan menggunakannya. Berbagai hal yang diteliti adalah kualitas layanan angkutan umum, fasilitas transit dan niatan atau ketertarikan seseorang menggunakan angkutan umum.

Selain fasilitas transit dan kualitas layanan, ada hal menarik lainya yang wajib diperhatikan, agar oprasional trem ini bisa berjalan dengan lancar pemerintah sebaiknya memberikan suatu kebijakan yang bisa membuat para pengguna kendaraan mobil pribadi bisa beralih menggunakan kendaraan umum misalnya diberikan kebijakan penekanan pada usia mobil yang sudah melewati batas tahun, sehingga mobil - mobil yang sudah melewati batas tahun tersebut tidak di perbolehkan beroperasi di jalan, menindak tegas pengguna mobil pribadi yang parkir di sembarangan tempat, menaikan pajak khusus mobil pribadi, dan melarang tegas Mobil Penumpang Umum (MPU) untuk parkir di sembarangan / menunggu (ngetem) penumpang karena harapanya nanti pemerinta bisa menyediakan tempat berhenti khusus dan tempat parkir (MPU).

Dalam menentukan rencana pembangunan tulang punggung angkutan umum massal Pemerintah Kota Surabaya memiliki kriteria-kriteria untuk menentukan jenis 


\section{NAROTAMA JURNAL TEKNIK SIPIL \\ e-ISSN: $2460-3430$ \\ VOLUME 2 NOMOR 2 NOVEMBER 2018}

transportasi massal yang akan dioperasikan di Surabaya. Transportasi massal yang akan dioperasikan di Surabaya harus memiliki daya tarik bagi masyarakat luas agar beralih dari kendaraan pribadi ke angkutan massal. Untuk mendukung daya tarik tersebut rencana angkutan massal yang akan diterapkan di Surabaya harus memiliki aksesibilitas wilayah yang luas, harus mempunyai kepastian waktu, memberikan kenyamanan bagi pengguna angkutan massal, dan menjamin rasa aman bagi pengguna angkutan massal. Moda angkutan umum massal harus memiliki aksesibilitas wilayah yang luas. Aksesibilitas wilayah yang luas dimaksudkan agar angkutan umum massal mampu menjangkau seluruh kawasan di Surabaya, mulai dari kawasan perkampungan hingga ke pusat perkotaan. Agar tujuan bisa tercapai, Pemerintah Kota Surabaya membagi tiga jenis angkutan umum massal sesuai wilayah yang akan diaksesnya. Tiga jenis angkutan umum massal tersebut adalah angkutan utama, angkutan cabang, dan angkutan ranting. Moda trem termasuk dalam angkutan utama, trunk (bus) termasuk dalam angkutan cabang, dan feeder (pengumpan/bus mini/sejenis bison) termasuk dalam angkutan ranting.

Rencana pembangunan trem sebagai tulang punggung angkutan umum massal di Surabaya tidak lepas dari berbagai pertimbangan. Peneliti mengelompokkan pertimbangan tersebut menjadi tiga jenis, yaitu pilihan teknologi yang berbasis rel dan kondisi jalan, cagar budaya, dan simpul perekonomian. Pemerintah Kota memilih trem untuk mengakomodasi pengguna transportasi di jalur linier utara-selatan dengan alasan daya angkut yang lebih banyak, adanya kawasan cagar budaya, dan simpul perekonomian di daerah Darmo hingga Tunjungan. Mengacu pada Perda RTRW No. 3 tahun 2007, pola pemanfaatan ruang wilayah berupa simpul perekonomian tersebar di kawasan Unit Pengembangan Kawasan VI dan VII, yaitu pusat pertumbuhan yang berada di Wonokromo dan Tunjungan, sehingga itu juga merupakan alasan Pemerintah Kota Surabaya tidak menempatkan trem di jalanan sekitar Diponegoro. Padahal dua kawasan tersebut juga memiliki kepadatan angkutan yang luar biasa terutama di jamjam sibuk. Area cagar budaya yang terdapat di kawasan Raya Darmo, termasuk pengalaman operasional trem pernah diterapkan pada jaman pemerintahan Hindia Belanda. Dua alasan tersebut menjadi landasan Pemerintah Kota Surabaya untuk mengoperasikan trem pada jalur ini. Pemerintah Kota Surabaya juga berencana untuk mengangkat kembali jalur trem yang ada di kawasan itu. Selain alasan cagar budaya dan historis, kondisi jalan di kawasan Unit Pengembangan Kawasan VI dan VII, yaitu pusat pertumbuhan yang berada di Wonokromo dan Tunjungan, sehingga itu juga merupakan alasan Pemerintah Kota Surabaya tidak menempatkan trem di jalanan sekitar Diponegoro. Padahal dua kawasan tersebut juga memiliki kepadatan angkutan yang luar biasa terutama di jam-jam sibuk. Area cagar budaya yang terdapat di kawasan Raya Darmo, termasuk pengalaman operasional trem pernah diterapkan pada jaman pemerintahan Hindia Belanda. Dua alasan tersebut menjadi landasan Pemerintah Kota Surabaya untuk mengoperasikan trem pada jalur ini. Pemerintah Kota Surabaya juga berencana untuk mengangkat kembali jalur trem yang ada di kawasan itu. Selain alasan cagar budaya dan historis, kondisi jalan di kawasan linier rute utara-selatan juga tidak memiliki banyak persimpangan seperti di jalur timur-barat atau sebaliknya. linier rute utara-selatan juga tidak memiliki banyak persimpangan seperti di jalur timur-barat atau sebaliknya.

\subsection{Perumusan Masalah}




\section{NAROTAMA JURNAL TEKNIK SIPIL \\ e-ISSN: $2460-3430$ \\ VOLUME 2 NOMOR 2 NOVEMBER 2018}

Perumusan masalah ini saya akan mendesain kuesioner lalu melakukan tes ke 30 Responden setelah itu pembetulan responden lalu melakukan survey ke 100 responden, menegelola data dan menganalisanya menggunakan program spss untuk mengetahui hubungan antara variabel independen dan dependen terhadap pengendara mobil pribadi. Sehingga perumusan masalah dalam rencana proposal ini adalah sebagai berikut:

1. Bagaimana uji validitas dan reliabilitas dari masing - masing variabel ?

2. Bagaimana pengaruh variabel independen terhadap variabel dependen secara parsial ?

3. Bagaimana pengaruh variabel independen terhadap variabel dependen secara simultan?

4. Apakah variabel - variabel independen dapat secara optimal membangkitkan ketertarikan pengguna mobil pribadi untuk beralih ke Trem Surabaya?

\subsection{Tujuan Penlitian}

Tujuan dan manfaat penelitian ini adalah sebagai berikut:

1. Mengetahui uji validitas dan reliabilitas dari masing - masing variabel.

2. Mengetahui pengaruh veriabel independen terhadap variabel dependen secara parsial.

3. Mengetahui pengaruh veriabel independen terhadap variabel dependen secara simultan.

4. Mengetahui variabel - variabel independen dapat secara optimal membangkitkan ketertarikan pengguna mobil pribadi untuk beralih ke Trem Surabaya.

\section{TINJAUAN PUSTAKA}

\subsection{Kendaraan}

Adalah kendaraan yang di gerakkan menggunakan mesin yang biasanya dipergunakan untuk mengangkut barang/ orang dari satu tempat ke tempat lainnya. Peralatan teknik dalam ketentuan ini dapat berupa motor atau peralatan lainnya yang berfungsi untuk mengubah suatu sumber daya energi tertentu menjadi tenaga gerak kendaraan bermotor yang bersangkutan. Pengertian kata berada dalam ketentuan ini adalah terpasang pada tempat sesuai dengan fungsinya. Termasuk dalam pengertian kendaraan bermotor adalah kereta gandengan atau kereta tempelan yang dirangkaikan dengan kendaraan bermotor sebagai penariknya. Secara umum, ada 2 (dua) kelompok besar moda transportasi (kendaraan) yaitu:

\section{Kendaraan pribadi}

Alat transportasi yang dikhususkan buat pribadi yang mempunyai hak atas kepemilikanya mempunyai kebijakan sendir. Contoh kendaraan pribadi seperti sepeda, sepeda motor, mobil, kapal, maupun pesawat terbang.

2. Kendaraan Umum (public transportation)

Alat transportasi yang digunakan untuk orang banyak, kepentingan bersama, menerima pelayanan bersama, mempunyai arah dan titik tujuan yang sama, serta terikat dengan peraturan trayek yang sudah ditentukan dan jadwal yang sudah ditetapkan dan para pelaku perjalanan harus wajib menyesuaikan diri dengan ketentuan-ketentuan tersebut apabila angkutan umum ini sudah mereka pilih. Contoh 


\section{NAROTAMA JURNAL TEKNIK SIPIL \\ e-ISSN: $2460-3430$ \\ VOLUME 2 NOMOR 2 NOVEMBER 2018}

kendaraan umum seperti : ojek sepeda motor, becak, bajaj, bemo, mikrolet, bus umum (kota dan antar kota), kereta api (kota dan antar kota), kapal feri, sungai \& laut, pesawat yang digunakan secara bersama.

Kendaraan bermotor sendiri adalah kendaraan yang digerakan oleh mesin yang terdiri dari kendaraan bermotor umum dan perseorangan, sedangkan kendaraan yang tidak bermotor adalah kendaraan yang digerakan oleh hewan contohnya : kuda, unta, gajah dll. (UU RI No. 22 Tahun 2009).

Angkutan umum adalah alat yang digunakan untuk memindahkan orang / barang dari satu tempat ketempat lain, tujuanya adalah untuk mengangkut sekelompok manusia menuju tempat yang akan dikehendaki, atau mengangkut barang dari satu tjuan ke tujuan lainya, prosesnya bisa menggunakan kendaraan atau tidak mengunakan kendaraan seperti diangkut oleh orang dengan mengunakansistem sewa atau bayar.

\subsection{Angkutan Umum}

Berdasarkan Peraturan Pemerintah No. 74 tahun 2014 tentang Angkutan Jalan dijelaskan angkutan adalah perpindahan orang dan/atau barang dari satu tempat ke tempat lain dengan menggunakan kendaraan di ruang lalu lintas jalan. Sedangkan kendaraan bermotor umum adalah setiap kendaraan bermotor yang digunakan untuk angkutan barang dan/atau orang dengan dipungut bayaran. Pengangkutan orang dengan kendaraan umum dilakukan dengan menggunakan mobil bus atau mobil penumpang dilayani dengan trayek tetap atau teratur dan tidak dalam trayek.

\subsection{Kereta Api}

Transportasi darat mulai dikembangkan dengan teknologi penggerak (sarana) sederhana berupa roda, yang selanjutnya dihasilkan beberapa tipe dan ukuran. Sejalan dengan perkembangan teknologi automotif, metal, elektronik dan informatika, manusia berhasil memanfaatkan sumber daya alam yang tersedia untuk menciptakan berbagai jenis moda angkutan dan lokomotif.

Angkutan transportasi darat hingga saat ini dikembangkan dalam 2 jenis moda angkutan, yaitu moda angkutan jalan raya dan moda angkutan jalan rel/kereta api. Perkeretaapian adalah satu kesatuan sistem yang terdiri atas prasarana, sarana, dan sumber daya manusia, serta norma, kriteria, persyaratan, dan prosedur untuk penyelenggaraan transportasi kereta api. (UU No.23, 2007)

Perkeretaapian merupakan angkutan yang ramah lingkungan, dengan emisi gas buang kecil dan pengembangan teknologi kereta berbasis energi listrik, memungkinan sebagai moda angkutan yang mampu menjawab masalah lingkungan hidup manusia di masa yang akan datang. Dapat dipergunakan sebagai pelayanan aktifitas khusus, karena daya angkut besar, dan memiliki jalur sendiri, sehingga perjalanan suatu aktifitas khusus dilaksanakan tanpa banyak memberi dampak sosial.

Kereta api adalah sarana perkeretaapian dengan tenaga gerak, baik berjalan sendiri maupun dirangkaikan dengan sarana perkeretaapian lainnya, yang akan ataupun sedang bergerak di jalan rel yang terkait dengan perjalanan kereta api. (UU No.23, 2007). Angkutan kereta api adalah kegiatan pemindahan orang dan atau barang dari satu tempat ke tempat lain dengan menggunakan kereta api. (Keputusan Menteri Perhubungan tentang Jalur Kereta Api No.52, 2000). 


\section{NAROTAMA JURNAL TEKNIK SIPIL \\ e-ISSN: $2460-3430$ \\ VOLUME 2 NOMOR 2 NOVEMBER 2018}

\subsection{Trem}

Trem merupakan kereta yang memiliki rel khusus di dalam kota. Trem yang berselang waktu 5-10 menit berangkat, bisa merupakan solusi untuk kemacetan. Rangkaian trem umumnya satu set (terdiri atas dua kereta) agar tidak terlalu panjang. Disebut Light Rail karena memakai kereta ringan sekitar 20 ton seperti bus, tidak seberat kereta api yang 40 ton. Letak rel berbaur dengan lalu-lintas kota, atau terpisah seperti bus-way, bahkan bisa pula layang (elevated) atau sub-way, hanya untuk sebagian lintasan saja.

Trem atau lengkapnya Trem Kota merupakan alternatif dalam menanggulangi kemacetan kota. Kendaraan ini biasanya hanya terdiri atas satu set (dua gerbong), karena harus menyesuaikan dengan keadaan lingkungan jalan kota yang tidak boleh terlalu panjang, karena berbaur dengan lalu lintas kota lainnya. Namun bisa saja dua set atau 4 kereta (HRT - Heavy Rail Transit - satu set adalah 4 kereta).

Berbagai keunggulan LRT adalah:

1. Dengan kendaraan ringan dan dapat dibuat oleh parik karoseri bus

2. Dapat berbaur dengan lalu-lintas kota

3. Dapat berbelok dengan radius kecil atau tajam (sekitar 15 meter, sehingga dapat menyelusuri bangunan tua pusat kota, sedangkan HRT minimum dengan radius 150 meter)

\subsection{Skala Likert}

Rensis Likert telah mengembangkan sebuah skala untuk mengukur sikap masyarakat di tahun 1932 yang sekarang terkenal dengan nama skala Likert. Skala Likert digunakan untuk mengukur sikap, pendapat, dan persepsi seseorang atau sekelompok orang tentang fenomena sosial. Dengan Skala Likert, variabel yang akan diukur dijabarkan menjadi indikator variabel. Kemudian indikator tersebut dijadikan sebagai titik tolak untuk menyusun item-item instrumen yang dapat berupa pertanyaan atau pernyataan. Jawaban setiap item instrumen yang menggunakan Skala Likert mempunyai gradasi dari sangat positif sampai sangat negatif, yang dapat berupa kata-kata antara lain: Sangat Penting (SP), Penting (P), Ragu-ragu (R), Tidak Penting (TP), Sangat Tidak Penting (STP).

Prosedur dalam membuat skala Likert adalah sebagai berikut:

A. Peneliti mengumpulkan item-item yang cukup banyak, relevant dengan masalah yang sedang diteliti, dan terdiri dari item yang cukup jelas disukai dan tidak disukai.

B. Kemudian item-item itu dicoba kepada sekelompok responden yang cukup representatif dari populasi yang ingin diteliti.

C. Responden di atas diminta untuk mengecek tiap item, apakah ia menyenangi $(+)$ atau tidak menyukainya (-). Respons tersebut dikumpulkan dan jawaban yang memberikan indikasi menyenangi diberi skor tertinggi. Tidak ada masalah untuk memberikan angka 5 untuk yang tertinggi dan skor 1 untuk yang terendah atau sebaliknya. Yang penting adalah konsistensi dari arah sikap yang diperlihatkan. Demikian juga apakah jawaban "setuju" atau "tidak setuju" disebut yang disenangi, tergantung dari isi pertanyaan dan isi dari item-item yang disusun.

D. Total skor dari masing-masing individu adalah penjumlahan dari skor masingmasing item dari individu tersebut. 


\section{NAROTAMA JURNAL TEKNIK SIPIL \\ e-ISSN: $2460-3430$ \\ VOLUME 2 NOMOR 2 NOVEMBER 2018}

E. Respon dianalisis untuk mengetahui item-item mana yang sangat nyata batasan antara skor tinggi dan skor rendah dalam skala total. Misalnya, responden pada upper $25 \%$ dan lower $25 \%$ dianalisis untuk melihat sampai berapa jauh tiap item dalam kelompok ini berbeda. Item-item yang tidak menunjukkan beda yang nyata, apakah masuk dalam skortinggi atau rendah juga dibuang untuk mempertahankan konsistensi internal dari pertanyaan.

\section{METODOLOGI PENELITIAN}

Sejalan dengan tujuan yang ingin diperoleh dalam penelitian ini, maka jenis penelitian ini adalah penelitian kuantitatif yang menekankan analisisnya pada data-data numerikal (angka) yang diolah dengan metode statistika (Azwar, 1997: 5). Adapun metode yang digunakan dalam penelitian ini adalah metode survai yaitu penelitian yang mengambil sampel dari satu populasi dan menggunakan kuesioner sebagai alat pengumpulan data yang pokok. Selain itu Interview (wawancara) juga digunakan dalam mengumpulkan informasi dari suatu populasi. Variabel dalam penelitian ini ada dua, pertama variabel independen yakni variabel bebas yang menjadi sebab terjadinya (terpengaruhnya) dependent variabel, sedangkan kedua adalah dependent variabel yakni variabel tak bebas yaitu variabel yang nilainya dipengaruhi oleh independent variabel.

Sumber data dalam sebuah penelitian maksudnya adalah dari mana data diperoleh (Arikunto, 2006: 129). Dalam penelitian ini sumber pengumpulan data didasarkan atas ada dua sumber, yaitu:

A. Sumber primer

Penulis memperoleh data primer melalui lembaran kuesioner yang disebar di kota Surabaya. Penyebaran kuesioner dilakukan langsung dari penulis kepada responden dan pengisian kuesioner dilakukan sendiri oleh responden (self - administered questionnaire).

B. Sumber sekunder

Adalah data yang dikumpulkan dari tangan kedua atau dari sumber-sumber lain yang telah tersedia sebelum penelitian dilakukan. Sumber ini meliputi komentar, interpretasi, atau pembahasan materi original, yang disebut dengan "second-hand information"(Silalahi, 2010: 289-291). Dalam penelitian ini sumber sekundernya adalah para pengguna mobil pribadi di Surabaya.

\section{Pembahasan}

Survey pendahuluan dalam audit internal adalah suatu cara yang digunakan untuk dapat mengetahui kerumitan operasi yang diaudit pada saat audit mulai dilakukan, sebagaimana yang kemudian mereka ketahui pada saat audit telah selesai. Secara sederhana survey pendahuluan dapat dipahami sebagai kegiatan yang dilakukan untuk mendapatkan informasi mengenai objek tertentu tanpa melakukan verifikasi secara inci. Pada penelitian ini penulis tidak mengalami perubahan kuesionar sehingga data responden yang didapat dari kuesioner bisa langsung diinput dan dianalisa menggunakan program spss versi 16.0

Tujuan pengujian ini adalah untuk mengetahui kevalidan angket / kuesioner dalam mengumpulkan data. Uji Validitas dilaksanakan dengan rumus korelasi bivariate person dengan alat bantu program SPSS versi 16.0. Item Kuesioner uji validitas dikatakan valid 


\section{NAROTAMA JURNAL TEKNIK SIPIL \\ e-ISSN: $2460-3430$ \\ VOLUME 2 NOMOR 2 NOVEMBER 2018}

jika nilai $r$ hitung $>r$ tabel pada nilai Sig. 5\%. Sebaliknya, item dikatakan tidak valid jika nilai $r$ hitung $<\mathrm{r}$ tabel pada nilai Sig. 5\%.

Uji reliabilitas digunakan menguji sejauh mana keandalan suatu alat pengukur untuk dapat digunakan lagi untuk penelitian yang sama. Penguji realiabilitas dalam penelitian ini adala dengan menggunakan rumus Alpha pada program SPSS 16.0 ditunjukkan oleh besarnya nilai alpha (a).

IUji parsial atau disebut juga uji $t$ dalam analisis regresi linear berganda bertujuan untuk mengetahui apakah variabel bebas $(\mathrm{X})$ secara parsial (sendiri-sendiri/masing-masing variabel) berpengaruh signifikan terhadap variabel terikat (Y). Dasar pengambilan keputusan uji $\mathrm{t}$ (parsial) sebagai berikut :

$>$ Jika nilai sig $<0,05$, atau $t$ hitung $>\mathrm{t}$ tabel maka terdapat pengaruh variable $\mathrm{X}$ terhadap variabel $\mathrm{Y}$.

Jika nilai sig $>0,05$, atau $\mathrm{t}$ hitung $<\mathrm{t}$ tabel maka tidak terdapat pengaruh variabel $\mathrm{X}$ terhadap variabel $\mathrm{Y}$.

Tabel 1. Rangkuman Hasil Uji (t Parsial) dari Masing - Masing Variabel

\begin{tabular}{|c|l|c|c|c|}
\hline No & \multicolumn{1}{|c|}{ Variabel } & t Hitung & t Tabel & Keterangan \\
\hline 1 & Rute Trem & 2,525 & 1,989 & Diterima \\
\hline 2 & Jarak Antar Halte & 1,918 & 1,989 & Ditolak \\
\hline 3 & Kapasitas Trem & 1,282 & 1,989 & Ditolak \\
\hline 4 & Tarif & 0,475 & 1,989 & Ditolak \\
\hline 5 & Jam Sibuk & 2,172 & 1,989 & Diterima \\
\hline 6 & Jam Non Sibuk & 0,349 & 1,989 & Ditolak \\
\hline
\end{tabular}

Sumber data diolah, (2017)

Uji simultan atau disebut juga uji $\mathrm{F}$ dalam analisis regresi linear berganda bertujuan untuk mengetahui apakah variabel bebas $(\mathrm{X})$ secara bersama-sama atau secara serempak (simultan) berpengaruh terhadap variabel terikat (Y). Dasar pengambilan keputusan uji $\mathrm{f}$ (simultan) sebagai berikut :

Jika nilai sig $<0,05$, atau $\mathrm{F}$ hitung $>\mathrm{F}$ tabel maka terdapat pengaruh variable $\mathrm{X}$ secara simultan terhadap variabel $\mathrm{Y}$.

$>$ Jika nilai sig $>0,05$, atau $\mathrm{F}$ hitung $<\mathrm{F}$ tabel maka tidak terdapat pengaruh variabel $\mathrm{X}$ secara simultan terhadap variabel $\mathrm{Y}$.

Tabel 2. Rangkuman Hasil Uji (f Simultan) dari Masing - Masing Variabel

ANONA $^{\text {b }}$

\begin{tabular}{|ll|r|r|r|r|r|}
\hline Model & & \multicolumn{1}{c|}{$\begin{array}{c}\text { Sum of } \\
\text { Squares }\end{array}$} & df & Mean Square & F & Sig. \\
\hline 1 & Regression & 74.837 & 6 & 12.473 & 2.828 & $.014^{2}$ \\
& Residual & 410.203 & 93 & 4.411 & & \\
& Total & 485.040 & 99 & & & \\
\hline
\end{tabular}

a. Predictors: (Constant), JAM NON SIBUK, TARIF, JAM SIBUK, RUTE TREM, KAPASITAS, JARAK ANTAR HALTE

b. Dependent Variable: KETERTARIKAN PENGGUNA MOBIL PRIBADI MENAIKI TREM

Sumber data diolah, (2017) 


\section{NAROTAMA JURNAL TEKNIK SIPIL \\ e-ISSN: $2460-3430$ \\ VOLUME 2 NOMOR 2 NOVEMBER 2018}

Uji normalitas adalah pengujian tentang kenormalan distribusi data. Penggunaan uji normalitas karena pada analisis statistik parametik, asumsi yang harus dimiliki oleh data adalah bahwa data tersebut harus terdistribusi secara normal. Maksud data terdistribusi secara normal adalah bahwa data akan mengikuti bentuk distribusi normal (Santosa\&Ashari, 2005:231).

Koefisien determinasi digunakan untuk mengetahui seberapa besar hubungan dari beberapa variabel dalam pengertian yang lebih jelas. Koefisien determinasi akan menjelaskan seberapa besar perubahan atau variasi suatu variabel bisa dijelaskan oleh perubahan atau variasi pada variabel yang lain (Santosa\&Ashari, 2005:125).

Tabel 3. Ringkasan Model

Model Summary

\begin{tabular}{|l|l|r|r|r|r|}
\hline $\begin{array}{l}\text { Mode } \\
1\end{array}$ & $\mathrm{R}$ & $\mathrm{R}$ Square & $\begin{array}{c}\text { Adjusted R } \\
\text { Square }\end{array}$ & $\begin{array}{c}\text { Std. Error of } \\
\text { the Estimate }\end{array}$ & $\begin{array}{c}\text { Durbin- } \\
\text { Watson }\end{array}$ \\
\hline 1 & $.393^{\mathrm{a}}$ & .154 & .100 & 2.10019 & 1.846 \\
\hline
\end{tabular}

a. Predictors: (Constant), JAM NON SIBUK, TARIF, JAM SIBUK, RUTE TREM, KAPASITAS, JARAK ANTAR HALTE

b. Dependent Variable: KETERTARIKAN PENGGUNA MOBIL PRIBADI MENAIKI TREM

Sumber : Data primer yang diolah (2017)

\subsection{Perumusan Hipotesis}

$\mathrm{H}_{1}=$ Terdapat pengaruh Rute Trem $\left(\mathrm{X}_{1}\right)$ terhadap ketertarikan pengguna mobil pribadi menggunakan Trem (Y)

$\mathrm{H}_{2}=$ Terdapat pengaruh Jarak Antar Halte $\left(\mathrm{X}_{2}\right)$ ketertarikan pengguna mobil pribadi menggunakan Trem (Y)

$\mathrm{H}_{3}=$ Terdapat pengaruh Kapasitas Penumpang Trem $\left(\mathrm{X}_{3}\right)$ terhadap ketertarikan pengguna mobil pribadi menggunakan Trem (Y)

$\mathrm{H}_{4}=$ Terdapat pengaruh Tarif Menaiki Trem $\left(\mathrm{X}_{4}\right)$ terhadap ketertarikan pengguna mobilpribadi menggunakan Trem (Y)

$\mathrm{H}_{5}=$ Terdapat pengaruh Jeda Waktu Kedatangan Trem pada Jam Sibuk $\left(\mathrm{X}_{5}\right)$ terhadap ketertarikan pengguna mobil pribadi menggunakan Trem (Y)

$\mathrm{H}_{6}=$ Terdapat pengaruh Jeda Waktu Kedatangan Trem pada Jam Non Sibuk $\left(\mathrm{X}_{6}\right)$ terhadap ketertarikan pengguna mobil pribadi menggunakan Trem (Y)

$\mathrm{H}_{7}=$ Terdapat pengaruh $\mathrm{X}_{1}, \mathrm{X}_{2}, \mathrm{X}_{3}, \mathrm{X}_{4}, \mathrm{X}_{5}$ dan $\mathrm{X}_{6}$ secara simultan terhadap ketertarikan pengguna mobil pribadi menggunakan Trem (Y)

\subsection{Hasil Pengujian Hipotesis}

A. Pengujian Hipotesis Pertama $\left(\mathrm{H}_{1}\right)$

Diketahui nilai Sig pada tabel 4.13 untuk pengaruh $\mathrm{X}_{1}$ terhadap $\mathrm{Y}$ adalah sebesar $0,013<0,05$ dan nilai $t$ hitung 2,525 $>\mathrm{t}$ tabel 1,989, sehingga dapat disimpulkan bahwa $\mathrm{H}_{1}$ diterima yang berarti terdapat pengaruh $\mathrm{X}_{1}$ terhadap $\mathrm{Y}$

B. Pengujian Hipotesis Kedua $\left(\mathrm{H}_{2}\right)$ 


\section{NAROTAMA JURNAL TEKNIK SIPIL \\ e-ISSN: $2460-3430$ \\ VOLUME 2 NOMOR 2 NOVEMBER 2018}

Diketahui nilai Sig tabel 4.13 untuk pengaruh $\mathrm{X}_{2}$ terhadap $\mathrm{Y}$ adalah sebesar 0,058 $>0,05$ dan nilai t hitung 1,918 $<\mathrm{t}$ tabel 1,989, sehingga dapat disimpulkan bahwa $\mathrm{H}_{2}$ ditolak yang berarti tidak terdapat pengaruh $\mathrm{X}_{2}$ terhadap $\mathrm{Y}$

C. Pengujian Hipotesis Ketiga $\left(\mathrm{H}_{3}\right)$

Diketahui nilai Sig tabel 4.13 untuk pengaruh $\mathrm{X}_{3}$ terhadap $\mathrm{Y}$ adalah sebesar 0,203> 0,05 dan nilai t hitung $1,282<\mathrm{t}$ tabel 1,989, sehingga dapat disimpulkan bahwa $\mathrm{H}_{3}$ ditolak yang berarti tidak terdapat pengaruh $\mathrm{X}_{3}$ terhadap $\mathrm{Y}$

D. Pengujian Hipotesis Keempat $\left(\mathrm{H}_{4}\right)$

Diketahui nilai Sig tabel 4.13 untuk pengaruh $\mathrm{X}_{4}$ terhadap $\mathrm{Y}$ adalah sebesar 0,636> 0,05 dan nilai t hitung $0,475<\mathrm{t}$ tabel 1,989 , sehingga dapat disimpulkan bahwa $\mathrm{H}_{4}$ ditolak yang berarti tidak terdapat pengaruh $\mathrm{X}_{4}$ terhadap $\mathrm{Y}$

E. Pengujian Hipotesis Kelima $\left(\mathrm{H}_{5}\right)$

Diketahui nilai Sig tabel 4.13 untuk pengaruh $\mathrm{X}_{5}$ terhadap $\mathrm{Y}$ adalah sebesar 0,032 $<0,05$ dan nilai t hitung 2,172 $>$ t tabel 1,989, sehingga dapat disimpulkan bahwa $\mathrm{H}_{5}$ diterima yang berarti terdapat pengaruh $\mathrm{X}_{5}$ terhadap $\mathrm{Y}$

F. Pengujian Hipotesis Keenam $\left(\mathrm{H}_{6}\right)$

Diketahui nilai Sig tabel 4.13 untuk pengaruh $\mathrm{X}_{5}$ terhadap $\mathrm{Y}$ adalah sebesar 0,728 $>0,05$ dan nilai t hitung 0,349 $<\mathrm{t}$ tabel 1,989, sehingga dapat disimpulkan bahwa $\mathrm{H}_{6}$ ditolak yang berarti tidak terdapat pengaruh $\mathrm{X}_{6}$ terhadap $\mathrm{Y}$

G. Pengujian Hipotesis Ketujuh $\left(\mathrm{H}_{7}\right)$

Berdasarkan output di atas diketahui nilai Sig. untuk pengaruh $\mathrm{X}_{1}, \mathrm{X}_{2}, \mathrm{X}_{3}, \mathrm{X}_{4}$ dan $\mathrm{X}_{5}$ secara simultan terhadap $\mathrm{Y}$ adalah sebesar $0,014<0,05$ dan nilai $\mathrm{F}$ hitung 2,828 $>2,31 \mathrm{~F}$ tabel, sehingga dapat disimpulkan bahwa $\mathrm{H}_{7}$ diterima yang berarti terdapat pengaruh $\mathrm{X}_{1}, \mathrm{X}_{2}, \mathrm{X}_{3}, \mathrm{X}_{4}$ dan $\mathrm{X}_{5}$ secara simultan terhadap $\mathrm{Y}$.

\section{Kesimpulan}

Berdasarkan analisis dan pembahasan mengenai ketertarikan pengguna mobil pribadi terhadap rencana operasional trem di Surabaya yang telah dijelaskan di bab sebelumnya pada penelitian ini, maka penulis memberikan beberapa kesimpulan berikut ini :

a) Berdasarkan hasil analisis Uji validitas dan Reliabilitas dapat disimpulkan bahwa semua item dalam angket / kuesioner analisis ini valid dan konsisten, meski ada salah satu Variabel yang tidak konsisten didalamnya tetap dapat digunakan sebagai instrumen penelitian.

b) Berdasarkan perhitungan Uji t (parsial) pada penelitian ini menunjukan bahwa variabel Jarak Antar Halte $\left(\mathrm{X}_{2}\right)$, Kapasitas Trem $\left(\mathrm{X}_{3}\right)$, Tarif Menaiki Trem $\left(\mathrm{X}_{4}\right)$, dan Jeda Waktu Tiba Trem di Jam Non Sibuk $\left(\mathrm{X}_{6}\right)$, tidak mempunyai pengaruh yang signifikan terhadap variabel Ketertarikan Pengguna Mobil Pribadi Menaiki Trem (Y) secara parsial, dan Rute Trem $\left(\mathrm{X}_{1}\right)$, dan Jeda Waktu Tiba Trem di Jam Sibuk $\left(\mathrm{X}_{5}\right)$ mempunyai pengaruh yang signifikan terhadap variabel Ketertarikan Pengguna Mobil Pribadi Menaiki Trem (Y) secara parsial yang ditunjukan pada besaran angka thitung $>\mathrm{t}$ tabel.

c) Berdasarkan hasil pengujian hipotesis Uji f (simultan) pada model regresi diatas, didapat nilai signifikansi model regresi secara simultan sebesar 0,014 , nilai ini lebih kecil dari significance level 0,05 (5\%), yaitu 0,014 $<0,05$. Selain itu dapat dilihat juga dari hasil perbandingan antara $\mathrm{F}$ hitung dan $\mathrm{F}$ tabel yang menunjukan $\mathrm{F}$ hitung sebesar 2,828 sedangkan F tabel 2,34. Dari hasil tersebut terlihat bahwa F hitung > 


\section{NAROTAMA JURNAL TEKNIK SIPIL \\ e-ISSN: $2460-3430$ \\ VOLUME 2 NOMOR 2 NOVEMBER 2018}

F tabel yaitu 2,828 $>2,34$ maka dapat di simpulkan bahwa secara simultan $\mathrm{H} 7$ diterima, artinya secara bersama - sama atau secara simultan variabel independen yaitu variabel $\mathrm{X}_{1}, \mathrm{X}_{2}, \mathrm{X}_{3}, \mathrm{X}_{4}, \mathrm{X}_{5}$ dan $\mathrm{X}_{6}$ berpengaruh secara signifikan terhadap variabel dependen yaitu variabel Ketertarikan Pengguna Mobil Pribadi Menaiki Trem (Y).

d) Berdasarkan Tabel "Model Summary" dapat disimpulkan bahwa variabel $X_{1}, X_{2}$, $\mathrm{X}_{3}, \mathrm{X}_{4}, \mathrm{X}_{5}$ dan $\mathrm{X}_{6}$ berpengaruh sebesar 0,154. Angka tersebut mengandung arti bahwa Rute Trem, Jarak Antar Halte Trem, Kapasitas Penumpang Trem, Tarif Menaiki Trem dan Jeda Waktu Tiba Trem berpengaruh terhadap Ketertarikan Pengguna Mobil Pribadi Menaiki Trem sebesar 15,4 \%, sedangkan sisanya 84,6\% dipengaruhi variabel lain yang diluar model regresi ini.

\section{DAFTAR PUSTAKA}

1. Agustin, T.F. (2006), Studi Evaluasi Pola Pergerakan Penumpang Dan Tingkat Pelayanan Kereta Api Komuter Surabaya - Sidoarjo - Porong. Malang: Jurusan S1 Teknik Sipil Universitas Muhammadiyah

2. Santosa, S. Menggunakan SPSS untuk Statistik Multivariat. Jakarta: Elex Media Computindo, 2006.

3. Setijaningrum, Erna dan kristiadi. Riset dan Pengukuran Kualitas Pelayanan. Surabaya : Revka Petra Media, 2012.

4. Anwari, M.S., Muhtadi, A., dan Wasono, S.B. (2016), Studi Pengaruh Rencana Fasilitas Transit Terhadap Niat Menggunakan Angkutan Massal Cepat Di Surabaya : Prodi S1 Teknik Sipil Universitas Narotama

5. Ferdiansyah, Ronando. (2009). Kemungkinan Peralihan Penggunaan Moda Angkutan Pribadi Ke Moda Angkutan Umum Perjalanan Depok-Jakarta: Institut Teknologi Bandung

6. Warpani, S. Merencanakan Sistem Pengangkutan. Bandung: ITB, 1990.

7. Nurtanto, E.R. "Kajian Pengoperasian Trem/LRT Sebagai Angkutan Massal Internal di Kawasan Kampus UGM.” Tesis, Universitas Gadjah Mada Yogyakarta, 2013.

8. Muhtadi, Adhi (2011), Basic Design Angkutan Umum Massal Perkotaan Metode Derivative Demand Untuk Menunjang Sistem Transportasi Berkelanjutan, Surabaya: Prodi S1 Teknik Sipil Universitas Narotama

9. Tamin, Ofyar. Sistem Angkutan Umum Berbasis Jalan Rel Sebagai Salah Satu Alternatif Pemecahan Permasalahan Transportasi Perkotaan. Seminar Regional Pengembangan Sistem Transportasi Yang Berkelanjutan. Universitas Kristen Petra Surabaya. 2012.

10. Wibisono, RE., Herijanto, W., Widyastuti, H. (2014). "Studi Pemodelan Trip Distibution Penumpang Penyeberangan Kapal Ferry di Pelabuhan Ujung Surabaya-Kamal Setelah Beroperasinya Jembatan Suramadu". Prosiding Seminar Nasional Teknik Sipil X2014, hal : 301-310.

11. Widoyoko. Tram Reborn, Mengenal: Moda Transportasi Massal Masa Depan. Depok: Ilalang Sakti Komunikasi, 2010.

12. Muhtadi, A., Wasono, S.B., dan Sri Wiwoho M. (2012), Evaluasi Pelayanan Bus dan MPU Kota Surabaya Untuk Menunjang Sistem Transportasi Berkelanjutan, Bandung: Prosiding Konferensi Nasional Pasca Sarjana Teknik Sipil (KNPTS) 2012, Institut Teknologi Bandung 


\section{NAROTAMA JURNAL TEKNIK SIPIL \\ e-ISSN: 2460-3430 \\ VOLUME 2 NOMOR 2 NOVEMBER 2018}

13. Muhtadi, A., Wasono, S.B. dan I Gede Arimbawa (2013), Fenomena The Theory of Planned Behavior Pelaku Perjalanan Untuk Menggunakan Bis Kota Surabaya, Surabaya: Prosiding Seminar Nasional MMT ITS XIX

14. Nasution (2003), Manajemen Jasa Terpadu, Cetakan Pertama, April 2004, Jakarta: Penerbit Ghalia Indonesia

15. Prihastomo, Bondan. (2014). Integrasi Moda Transportasi Trem Dalam Ruang Kota (Studi Kasus Ruang Jalan Dr. Rajiman dan Jalan KH. Agus Salim Surakarta): Jurusan Teknik Arsitektur Universitas Indo Global Mandiri

16. surya.co.id (27 November 2010), Jalanan Surabaya Tak Sanggup Tampung Jumlah Kendaraan, diakses tanggal 1 Maret 2013

17. Undang Undang No. 22 tahun 2009 tentang Lalu Lintas dan Angkutan Jalan (LLAJ)

18. Undang Undang No. 14 tahun 1992 tentang Lalu Lintas dan Angkutan Jalan (LLAJ)

19. Peraturan Pemerintah No. 41 tahun 1993 tentang Angkutan Jalan

20. Peraturan Pemerintah Republik Indonesia No. 55 Tahun 2012 Tentang Kendaraan

21. Peraturan Pemerintah Republik Indonesia No. 74 Tahun 2014 Tentang Angkutan Jalan

22. Peraturan Mentri Perhubungan Republik Indonesia No. PM 48 Tahun 2015 Tentang Standar Pelayanan Minimum Angkutan Orang Dengan Kereta Api

23. Peraturan Pemerintah Republik Indonesia No. 29 Tahun 2015 Tentang Standar PelayananMinimal Angkutan Orang dengan Kendaraan Bermotor Umum Dalam Trayek

24. bisnis.tempo.co (2013), Wali Kota Surabaya Cari Investor Trem dan Monorel, Publikasi pada Rabu 31 Juli 2013 